\title{
Michel Brix, Sur onze lettres inédites de Nerval à Francis Wey
}

\section{Franca Zanelli Quarantini}

\section{(2) OpenEdition}

1 Journals

\section{Edizione digitale}

URL: http://journals.openedition.org/studifrancesi/6358

DOI: 10.4000/studifrancesi.6358

ISSN: 2421-5856

\section{Editore}

Rosenberg \& Sellier

\section{Edizione cartacea}

Data di pubblicazione: 1 novembre 2010

Paginazione: 571

ISSN: 0039-2944

\section{Notizia bibliografica digitale}

Franca Zanelli Quarantini, «Michel Brix, Sur onze lettres inédites de Nerval à Francis Wey», Studi Francesi [Online], 162 (LIV | III) | 2010, online dal 30 novembre 2015, consultato il 08 janvier 2021. URL: http:// journals.openedition.org/studifrancesi/6358; DOI: https://doi.org/10.4000/studifrancesi.6358

Questo documento è stato generato automaticamente il 8 janvier 2021.

\section{(c) $(1) \&$}

Studi Francesi è distribuita con Licenza Creative Commons Attribuzione - Non commerciale - Non opere derivate 4.0 Internazionale. 


\title{
Michel Brix, Sur onze lettres inédites de Nerval à Francis Wey
}

\author{
Franca Zanelli Quarantini
}

\section{NOTIZIA}

MICHEL BRIX, Sur onze lettres inédites de Nerval à Francis Wey, in Promenades et Souvenirs. Pour Gabrielle Chamarat, textes réunis par G. BARTHÉLEMY et J.-L. CABANÈs, Université Paris Ouest - Nanterre La Défense, «Littérales», hors série, 2009, pp. 201- 214.

1 Tra il 1850 e il 1851 Gérard de Nerval è un uomo di teatro senza fortuna: deluso dall'échec di De Paris à Pékin, una pièce scritta in collaborazione e rifiutata all'ultimo momento dall'Odéon, riesce a far rappresentare Une Nuit blanche, il cui testo è andato perduto e che subì dopo pochissime serate il veto della censura. Provato dai mancati successi, qualche mese dopo Nerval ha una crisi importante e lo confida in una lettera all'amico e letterato Francis Wey, lo stesso a cui indirizza undici lettere da poco ritrovate e battute all'asta nel 2007 all'Hôtel Drouot per 50.000 euro. In tre di esse, datate 1851, malgrado le personali sconfitte Gérard si prodiga tramite Houssaye per aprire a Wey la via del teatro (ma la pièce di quest'ultimo sarà, a sua volta, un «four retentissant»). Più interessante l'altro gruppo di messaggi datati 1853, in una delle quali, parlando di un suo viaggio nella Bièvre, Gérard annuncia di aver «à peu près fini la nouvelle qui me préoccupait tant»: come ipotizza l'A. si tratta probabilmente di Sylvie. Nelle rimanenti lettere, inviate dalla maison del dottor Blanche nella seconda metà del 1853 - un periodo difficile per la salute dello scrittore - Gérard riferisce del proprio stato con la consueta, toccante sincerità: «Maintenant je vais bien mais pas assez pour sortir», vi si legge tra l'altro. Ma la trascrizione integrale delle undici lettere non è ancora stata effettuata. 